\title{
Testis Torsiyonlu Olgularda 4.5 Yıllık Deneyimlerimiz

\author{
4.5 Years' Experiences in Cases with Testicular Torsion
}

\author{
Gökmen KURT ${ }^{1}$, Ayşenur Cerrah CELAYİR ${ }^{1}$, Ceyhan ŞAHİN ${ }^{1}$, Koray PELINN ${ }^{1}$ \\ 1. Zeynep Kamil Kadın ve Çocuk Hastalıkları Eğitim ve Araştırma Hastanesi, Çocuk Cerrahisi Kliniği, İstanbul
}

\section{ÖZET}

Amaç: Testisin vasküler pedikülü etrafinda dönmesi sonucu meydana gelen testis torsiyonu, akut skrotumun sonuçları açısindan en önemli nedenlerinden biridir. Bu çalışmada kliniğimizde opere edilen testis torsiyonu olgularının özellikleri ve sonuçları literatür eşliğinde tartışıldi.

Materyal ve Metod: Ocak 2006 - Temmuz 2010 tarihleri arasinda testis torsiyonu nedeni ile kliniğimizde opere edilen olgular yaş, yakınma, öykü, taraf, muayene bulguları, tanı yöntemleri, ameliyat bulguları ve ameliyat sonrası takipleri açısından değerlendirildi.

Bulgular: Dört buçuk yılda kliniğimizde opere edilen testis torsiyonlu 24 olgudan birinde bilateral torsiyon olması nedeniyle toplam 25 testis opere edilmişti. Çocuklartn 3 'ünde şüpheli travma öyküsü mevcut olup, fizik muayenelerinde şişlik, ağrı, klzarlkllk gibi nonspesifik bulgular vard. Olguların 9'u yenidoğan (\%37.5), 3'ü adolesan (\%12.5), diğer 12 olgu 1 ay-10 yaş aralığında idi (\%50). 25 testiste torsiyonlarn 16’st sol (\%64), 9'u sağda (\%36) idi. Olgularımızın yaşları bir saatlik yenidoğan ile 16 yaş arasında değişmekte idi. 14 tetiste (\%56) orşiektomi; 10 olgudaki 11 testiste (\%44) orşiopeksi uyguland.

9 yenidoğandan 7'si doğumundan itibaren birici gün içinde opere edildi. Yenidoğan torsiyonlarının hepsi ekstravajinal idi. Torsiyonlar 360-720 derece arasında değişmekte idi; çoğunda 540 dereceden fazlaydr. Sadece iki yenidoğanda orşiopeksi yapıldl; diğerlerinde orşiektomi gerekti. Orşidektomi materyallerinin histopatolojik incelemelerinde tüm testislerde hemorajik infarktüs saptand. İki yenidoğanda yapılan üç orşiopeksi den ikisi geç dönemde atrofiye gitti. Sonuçta torsiyone olmuş 25 testisten 9'unda testis viabilitesi korunmuş oldu.

Sonuç: Testis torsiyonu, gelişen teknolojiye rağmen gerek tanı, gerek operasyon endikasyonu açısından halen aileler ve çocuk cerrahları için stres kaynağı olmaya devam etmektedir.

Anahtar Kelimeler: testis; torsiyon; çocuk; yenidoğan; orşiektomi; detorsiyon

İletişim Bilgileri

Sorumlu Yazar: Prof. Dr. Ayşenur Cerrah CELAYiR

Yazışma Adresi: Şakacı Sok. Mehmet Sayman Ap. No: 61-B,

D:8, Kazasker, Kadıköy, İstanbul, 34736

E-posta: celayiraysenur@gmail.com

Tel: +90 (532) 3265669

Makale Geliş Tarihi: 22.02.2017

Makale Kabul Tarihi: 19.04.2017

DOI: http://dx.doi.org/10.16948/zktipb.293307

\section{ABSTRACT}

Introduction and Aim: Testicular torsion occurring as a result of the rotation of the vasculer pedicle is the most important cause of acute scrotum results in terms of. In this study, cases with testicular torsion who had operated at our department and it's outcomes were discussed.

Material and Methods: Clinical records of all cases with testicular torsion who had operated at our department between January 2006 and July 2010 were evaluated as retrospectively in regard to age, history, side, symptoms, examination findings, surgical indications, operatively findings, histopathological results and outcome.

Results: 25 testes torsion in 24 cases were operated at our department during 4.5 years period. Ages of patients ranged an 1 hour's newborn to a 16 years old boy. 9 of patients (37.5\%) were newborn; and 3 were adolescent (12.5\%); the other $12 \mathrm{pa}$ tients remained between One and 11 years old (50\%) one of these newborns had bilateral testes torsion. 14 testes underwent orchiectomy (44\%) and 11 testes of 10 patients underwent orchidopexy (56\%). 16 of testes torsion were on left side (64\%), and 9 were on right side (36\%). One patient aged 7 years old had torsion of appendix testes on left side. Torsion degree was changed between 360-720 degree; and bigger than 540 degree in most patients. All newborn torsions were extravaginal. Orchidopexy was created in elder boys; three of them had a suspicious of trauma, and findings of the phisical examination were unspesific for the torsion. In histopathologic examinations of all orchidectomic testes were determined hemoragic infarctus. Two of the three testis with orchiopexy in two neonates went to atrophy in the late period. Overall, testicular viability of 9 testes in 25 testes was preserved.

Conclusion: Despite emerging technologies, testicular torsion is still continues to be a source of stress for families and pediatric surgeons both in terms of operation indication and recognize.

Keywords: testes; torsion; child; newborn; orchidectomy; detorsion 


\section{GİRIŞ}

Testisin vasküler pedikülü etrafında dönmesi sonucu meydana gelen testis torsiyonu, akut skrotumun en sık nedeni olmasa da sonuçları açısından en önemli nedenidir. Testis torsiyonu akut skrotum bulguları ile karşımıza çıkar. Akut skrotumun ayırıci tanısinda organ kaybı açısından en önemlisi testis torsiyonudur $(1,5)$. Testis torsiyonu en sıklıkla yenidoğan ve adölesan döneminde görülmek üzere bimodal dağ1lım gösterir (1).

Bu çalışmada kliniğimizde opere edilen testis torsiyonu olgularının genel özellikleri literatür eşliğinde tartışıldı.

\section{MATERYAL ve METOD}

Ocak 2006 ve Temmuz 2010 yılları arasında 4.5 yıllık sürede testis torsiyonu nedeni ile kliniğimizde opere edilen olgular yaş, yakınma, öykü, taraf, muayene bulguları, tanı yöntemleri, ameliyat bulguları, histopatolojik değerlendirme ve ameliyat sonrası takipleri açısından değerlendirildi. Tüm olgularda ameliyat esnasinda detorsiyon sonrası en az 15 dakika sicak kompres uygulaması ve dolașım kontrolü sonrası orşideopeksi veya orşiektomi yapılmaktaydı. Bulgular yüzdelik dağılımlarına göre analiz edildi.

\section{BULGULAR}

Ocak 2006'dan Temmuz 2010'a kadar 4.5 y1llı sürede kliniğimizde opere edilen testis torsiyonu olgularının sayıs1 24 olup; bir yenidoğanda bilateral testis torsiyonu olması nedeniyle toplam 25 testis opere edilmişti. Olguların 9'u yenidoğan (\%37.5), 3'ü adolesan (\%12.5), diğerleri 1ay-10 yaş aralığında (\%50) idi. Olgularımızın yaşları bir saatlik yenidoğan ile 16 yaş arasında değişmekte idi. Olgular, yenidoğan yaş dönemi ve adolesan yaş dönemi olmak üzere iki bölüm halinde değerlendirildiğinde, yenidoğanların yaşları 1 saat ile 5 gün arasında değişmekte olup yaş ortalamas 33 saat idi. Adölesan olguların yaşları 10 ile 16 yaş arasında değişmekte olup yaş ortalaması 13.4 yaş idi, diğer olguların yaş ortalaması 4.2 yaş idi. Hastaların yaş dağılımı ve torsiyon tarafı özellikleri Tablo 1'de özetlenmiştir (Tablo 1).

Üç olguda şüpheli travma öyküsü mevcut olup fizik muayenelerinde şişlik ağrı kızarıklık gibi nonspesifik bulgular vard,, bu olgularda orşopeksi yapılmıştı. Yenidoğan olgularının klinik tanısı fizik muayene ile konuldu ve başvuru olur olmaz ilk saat içinde operasyona alındılar, hiçbirinde ameliyat öncesi skrotal doppler US istenilmedi. 9 yenidoğandan 7'si doğumundan itibaren ilk 24 saat içinde müracaat etmişlerdi ve müracaatının ilk saatinde opere edildiler. Yenidoğan torsiyonlarının hepsi ekstravajinal torsiyon idi. Bilateral testis torsiyonlu olguda sol taraf 360 derece, sağ taraf 720 derece torsiyone olup diğer olgularda testis torsiyonu 540 dereceden fazla idi, tamamına orşiektomi yapıldı. Diğer 2 yenidoğan, 3. ve 5. gün opere edildi. Hidrops fetalisli doğan bilateral testis torsiyonlu olguda aynı zamanda bilateral skrotal ödem mevcuttu.

\begin{tabular}{|c|c|c|c|}
\hline Yaş & $\begin{array}{l}\text { Sağ Torsiyon } \\
\text { n:10 (\%44) }\end{array}$ & $\begin{array}{c}\text { Sol Torsiyon } \\
\text { n:15 (\%56) }\end{array}$ & $\begin{array}{c}\text { Torsiyone Testis } \\
\text { n:25 (\%100) }\end{array}$ \\
\hline $\begin{array}{c}\text { 0-28 Gün } \\
\text { n:9 (\%37.5) }\end{array}$ & 5 & 5 & $10(\% 40)$ \\
\hline $\begin{array}{l}\text { 1ay-10 Yaş } \\
\mathrm{n}: 12(\% 50)\end{array}$ & 1 & 11 & $12(\% 48)$ \\
\hline $\begin{array}{c}\text { 11yaş-16 Yaş } \\
\mathrm{n}: 3 \text { (\%12.5) }\end{array}$ & 3 & 0 & $3(\% 12)$ \\
\hline
\end{tabular}

Olguların birinde bilateral olmak üzere toplam 25 testis torsiyone olmuştu; torsiyonların 16's1 sol (\%64), 9'u sağda (\%36) idi. 14 olguda orşiektomi (\%56), 10 olguda 11 orşiopeksi $(\% 44)$ orşiopeksi uygulandı. Yenidoğanlardan birinde eș zamanlı olarak bilateral testis torsiyonu olmasi dolayisiyla toplam 11 testis de (\%44) orşiopeksi yapılmıștı. Orşiektomi materyallerinin histopatolojik incelemelerinde tüm testislerde hemorajik infarktüs saptandi. Bilateral testis torsiyonlu yenidoğanda her iki tarafa orşiopeksi uygulandı; ameliyat sonrası ikinci ayında skrotal doppler US takiplerinde testis boyutunun normal olduğu ve arterial akımının minimal olduğu saptand,, ancak iki yıl sonra yapılan US'de 720 derece torsiyon olmuş sağ testis'in atrofiye gittiği ve akım hiç olmadı̆̆ 360 derece torsiyone olmuş sol testis boyutlarının ise yaşına uygun normal boyutta olduğu tesbit edildi. Bilateral torsiyonlu yenidoğan ile beraber 2 yenidoğan hariç tüm yenidoğanlarda orşiektomi yapılmıştı. Sol detorsiyon ve orşiopeksi yapılan diğer yenidoğanda 2 yaşında sağ inguinal herni operasyonu esnasinda sol testisin atrofik bulunması nedeni ile geç orşiektomi uygulandi. Böylelikle geç dönem dahil 15 olguda (\%41.6) orşiektomi uygulanmış oldu; bilateral torsiyonlu yenidoğanda ise bir testis atrofiye gitti. Böylelikle 24 hastada; 25 testisten 16 testis $(\% 60)$ kaybedilmiş oldu, testis viabilitesi \%44 (11 testis) idi. Hastaların ameliyat sonuçları ve özellikleri Tablo 2'de; testislerin geç dönem viabilite durumları Tablo 3'de özetlenmiştir (Tablo 2 ve 3 ). 
Tablo 2: Testis torsiyonlu olgularında tarafları ve yapılan ameliyat yöntem tabloda özetlenmiştir. Bilateral testis torsiyonu olgusu tabloda sağ ve sol tes tis grubuna bir adet ilave edilerek gösterilmiştir.

\begin{tabular}{|c|c|c|c|}
\hline & $\begin{array}{c}\text { Sağ Testis } \\
\mathrm{n}: 9(\% 36)\end{array}$ & $\begin{array}{c}\text { Sol Testis } \\
\mathrm{n}: 16(\% 64)\end{array}$ & $\begin{array}{c}\text { Toplam } \\
\text { Torsiyone Testis } \\
\mathrm{n}: 25\end{array}$ \\
\hline $\begin{array}{c}\text { Orşiopeksi } \\
\mathrm{n}: 11\end{array}$ & 5 & 6 & $11(\% 56)$ \\
\hline $\begin{array}{c}\text { Orşiektomi } \\
\mathrm{n}: 14\end{array}$ & 4 & 10 & $14(\% 44)$ \\
\hline
\end{tabular}

Tablo 3: Torsiyone olmuş testislerin erken dönemde $11^{\prime} \mathrm{i}$ viabil iken; geç dönemde 9'u viabil bulundu.

\begin{tabular}{|c|c|c|c|}
\hline & $\begin{array}{c}\text { Sağ } \\
\text { Testis } \\
\mathrm{n}: 9(\% 36)\end{array}$ & $\begin{array}{c}\text { Sol } \\
\text { Testis } \\
\mathrm{n}: 16(\% 64)\end{array}$ & $\begin{array}{c}\text { Toplam Testis } \\
\mathrm{n}: 25\end{array}$ \\
\hline Orşiopeksi & $\begin{array}{c}\text { Sağ } \\
\text { Orşiopeksi } \\
\mathrm{n}: 5\end{array}$ & $\begin{array}{c}\text { Sol } \\
\text { Orşiopeksi } \\
\mathrm{n}: 6\end{array}$ & $11(\% 44)$ \\
\hline $\begin{array}{c}\text { Erken dönem } \\
\text { testis viabilitesi } \\
\text { mevcut }\end{array}$ & 5 & 6 & $11(\% 44)$ \\
\hline $\begin{array}{c}\text { Geç dönem } \\
\text { testis viabilitesi } \\
\text { mevcut }\end{array}$ & 4 & 5 & $9(\% 36)$ \\
\hline \multicolumn{2}{|c|}{} & & \\
\hline
\end{tabular}

Orşiopeksi yapılan 10 hastadaki 11 detorsiyone edilmiş testislerinin son durumları ameliyattan ortalama 4 yıl sonra ayrıca değerlendirildi. Ancak 6 olgunun hastane kayıtlarındaki adres bilgilerinden kendilerine ulaşılamadığından geç dönem detorsiyone edilmiş testislerinin son durum değerlendirilmesi yapılamadi. Geç dönem değerlendirilmesi yapılan 4 olgunun ikisi yenidoğan döneminde opere edilmiş olgulard1; bu iki olgunun detorsiyon yapılmış 3 testisinin ikisi geç dönemde tamamen atrofiye gitmiști; bir tarafı tamamen atrofik olan bilateral torsiyonlu hastanın diğer detorsiyone edilmiş testisinin viabilitesti mevcut,olup testis boyutları yaşıtlarına uygun idi. Diğer iki olgunun ise geç dönem US'de detorsiyone edilen testis boyutlarının, karşı testis boyutlarının yaklaşık \%50'si kadar olduğu tesbit edildi. Yani, dört olgunun beş testisinden ikisi tamamen atrofiye gitmiş, ikisi viabil olup karş1 testisinin $\% 50$ boyutlarında idi, birinde ise yaşıtlarına uygun boyutlarda idi. Kontrola gelmeyen diğer altı olgunun testislerinin viabl olduğu en iyi ihtimallle kabul edilse dahi toplamda detorsiyon yapilmiş 11 testisten sadece birisi tamamen atrofiye gitmişti; özetle, 24 olguda 25 testiste erken dönem testis viabilitesi \%44 (11 testis) iken geç dönemde testis viabilitesi \%36 (9 testis) olduğu bulundu.

\section{TARTIŞMA}

Testis torsiyonu, erkek sperm üretme organ1 olan testislerin bir ya da ikisinin kendi ekseni etrafında birkaç tur atabilmesi sonucunda testise kan getiren damarların bask1 altında kalması ve testisin beslenemeyerek giderek reperfüzyon hasarına uğramasına denilmektedir. Torsiyonun derecesine göre testislerde kan akımı azalabilir veya tamamen kesilebilir. Testisler, kansız kalması durumunda en fazla 4-6 saat içerisinde etkilenmekte ve en geç 12-16 saatte reperfüzyon hasarı oluşmaya başlamaktadır $(1,5)$.

Torsiyon oluştuğu zaman ani ve şiddetli bir kasık sancisıyla genellikle hastalık kendini gösterir. Bunun yanında çocuk veya gençler testis dönmesiyle karşılaștığı zaman bu şiddetli ağrıya eşlik eden genellikle bulantı, kusma, yumurtanın yukarı doğru çekilmesi yani eski haline göre daha yukarıda durması ve uzun ekseninin yukarıdan aşağıya değil de sağdan sola şeklinde yan dönmesiyle dikkat çeker. Bu belirtilerin yanında ateş de gelişebilir. Skrotum derisinde kızarıklık testis torsiyonunun orşiepididimitle karıșmasına neden olan önemli bir belirtisidir $(5,10)$.

Testis dönmesi sorunu çoğunlukla yeni doğan döneminde ve ergenlik çağında görülür. Testis torsiyonu olguları sıklıkla hayatın iki döneminde karşımıza çıkmaktadır (1). Yenidoğan döneminde ve ergenlik dönemindeki bu iki farklı zamanlarda torsiyon olmasinın etyolojik nedenleri de farkl1lıklar göstemektedir (5). Bizim olgularımızda ağırlıklı olarak yenidoğan dönemi hastalardan oluşmaktaydı. Sonuçlarımız incelendiğinde bulgularımızın literatürle uyumlu olduğu görülmektedir. Literatürden farkl1 olarak $\% 5$ olarak belirtilen bilateral yenidoğan testis torsiyonu oran1, serimizdeki yenidoğanlarda \%11.1 oranında izlendi $(3,4)$. Olgu sayısının azlığının bu fark1 yarattı̆̆1 düşünülmektedir.

Hastanın ilk müracaat anında öykü ve fizik muayene bulgularına göre; testis torsiyonunun ayırıcı tanısinın yapılması organ korunması veya kaybı açısından hayati önem taşımaktadır. Ayırıcı tanıda testisin ve/veya üzerinde bulunan sperm keseciklerinin (epididim) iltihaplanmas1, apendiks testis torsiyonu, akut hidrosel, idiopatik skrotal ödem, travmatik hematom, testis tümörleri, başka bazı hastalıkların testis ve torbalara yansıyan belirtileri, örneğin aynı tarafta fitığ 1 olan hastada perfore apandisit ve skrotal apse gibi durumlar yer almaktadır. Bu olgularda fizik muayene bulguları ile pek çoğu dişlan sa da en sıklıkla testis torsiyonu orşiepididimit ile karıştırılabilmektedir $(8,14)$. Birçok testis torsiyonlu olgunun orşiepididimit ön tanısıyla tedavi edilmesi; reperfüzyon hasarı ile testis kabına yol açar. Özellikle hidrops fetalisli olgularda jeneralize ödem ve skrotal ödemin olmasi testis torsiyonu tanisinda gecikmelere neden olabilmektedir. Nitekim serimizdeki tüm yenidoğan olgularında reaksioner veya fizyolojik hidrosel mevcut idi. Yenidoğanlarda hidrosel varlığının hastaların cerrahi konsültasyon zamanını geciktirmektedir. 
Akut skrotumlu olgularda; fizik muayene yanısıra testiste kanlanma varlığının Doppler ultrasonografi veya testis Sintigrafisi ile gösterilmesi testis torsiyonunu dişlamak açısından çok faydalıdır (10-12). Tanı yöntemlerinden özellikle testis sintigrafisinin güvenilirliği halen tartışmalıdır, ayrıca nöbet şartlarında sintigrafinin genellikle pekçok merkezde yapılamıyor olması veya bazı merkezlerde nöbet şartlarında Doppler ultrasonografinin dahi yapılamaması çok büyük dezavantaj oluşturmaktadır. Yine aynı șekilde güvenilirliği deneyimli ellerde \%100 olan Doppler US'nin yaygın kullanılmaması, bu konuda yeterli sayıda deneyimli kişilerin olmaması ve Doppler US'nin 7 gün 24 saat yapılamaması nedeniyle testis torsiyonunda tanı ve tedavide halen altın standart; torsiyondan șüphelenmesi ve acil olarak cerrahi eksplore edilmesidir (13).

Bizim hastanemiz ve kliniğimiz şartlarında Doppler US sadece mesai saatleri içinde yapılabiliyor oplması nedeniyle fizik muayene bulguları ile testis torsiyonu düşünülen her olguda acil eksplorasyon yapılmaktadır. Nitekim yenidoğan olgularımızın yedisinde ultrasonografi veya Dopplerr US yapılmadan ilk gün içerisinde opere edilmişlerdi.

Testis torsiyonunda testiste reperfüzyon hasarı gelişmeden hastanın opere edilmesi detorsiyon sonrası testisin kurtarılma şansını arttırmaktadir $(4,8,9)$. Testis torsiyonunda ilk 6-8 saatte operasyon büyük oranda (\%85-97) testisi kurtarabilmektedir $(8,14)$. Elbette süre ile birlikte torsiyonun derecesi de hasarlanmada belirleyici etkendir. 24 saatten uzun öyküsü olanlarda testis canlılığ 1 \% 10'un altındadır. Diğer yandan yenidoğan testisinin normal kan akımının Doppler US ile değerlendirilmesinin bazı teknik güçlükleri vardır. Halen ülkemizde ve dünyada torsiyon şüphesi ile yapılan eksplorasyonların 2/3'ü negatif olabilmektedir $(13,14)$. Bizim olgularımız arasında negatif eksplorasyon olmamıștır.

Yenidoğan dönemindeki torsiyonların \%92 sinin nedeni ekstravajinal torsiyonlardır (6). Bizim yenidoğan hastalarımızdaki torsiyonlar da ekstravajinal torsiyon olup; yedi olguda erken dönemde orşiektomi yapılması gerekmişti, bir olguda ise geç orşiektomi yapılması gerekmişti. Adölesan dönemindeki torsiyonların çoğu intravajinaldir (7). Adolesan dönemi olgularımızdaki torsiyonların tümü intravajinal torsiyon idi; ancak 16 yaşındaki olgumuzda ekstravaginal torsiyon saptanmıştı.

Testis torsiyonlu olgularda cerrahi operasyon esnasında karşı testisin fiksasyonu konusunda literatürde değișik bilgiler olmakla beraber genel eğilim karşı tarafın eksplorasyonu şeklin- dedir. Aynı şekilde orşidopeksi sonrasında atrofiye giden testislerde antisperm antikorlarının karşı testisin sperm üretimi üzerindeki olumsuz etkileri nedeniyle eksize edilmesi gerekliliği; ya da atrofik de olsa hormonal aktivitenin devam edeceği için yerinde bırakılması gerektiği hususunda literatürde de henüz bir fikir birliği oluşmamıștır $(4,15-17)$. Bu çalışmanın yapıldığı dönem; eğitim kliniği olmamızın ilk yıllar1 olması ve kliniğimizdeki, uzmanların farklı merkezlerden uzmanlıklarını almaları nedeniyle ilk operasyonda karşı testisin fiksasyonu, geç dönemde atrofiye giden testisin eksizyonu veya çıkarılmaması konusunda hastaya yaklaşımlarda farkl1lıklar olabilmekteydi.

Ancak son y1llarda atrofik testislerin hormonal fonksiyonlarını devam ettirebileceği görüşlerinin artmasına paralel olarak, kliniğimizde de atrofik testisin çıkarılması yönündeki girişimlerden kaçınılmaktadır.

Sonuç olarak akut skrotum, gelişen teknolojiye rağmen gerek tanı, gerek operasyon endikasyonu açısından hem aileler hem de çocuk cerrahları için halen stres kaynağı olmaya devam etmektedir. Operasyon esnasinda testis tamamen nekrotik değil ise orșiopeksi yapılması; düșük oranlarda da olsa testis viabilitesinin korunmas1nı sağlayacaktır.

\section{KAYNAKLAR}

1. Özdemir K, Savaş Ç. Çocuklarda akut skrotum. SDÜ Tıp Fakültesi Derg 2000; 7(4): 50-60.

2. Celayir AC, Sander S, Eliçevik M, Ünal M. Is Surgery Indicated In Delayed Acute scrotum? 14 Years experience From A maternal and children's hospital. J Urol 2007; 177(6): 2296-9.

3. Baglaj M, Carachi R. Neonatal bilateral testicular torsion: A plea for emergency exploration. J Urol. 2007; 177(6): 2296-9.

4. Djahangirian O, Ouimet A, Saint-Vil D. Timing and surgical management of neonatal testicular torsions. J Pediatr Surg 2010; 45(5): 1012-5.

5. Başaklar AC. Bebek ve Çocukların Cerrahi ve Ürolojik Hastalıkları. Cilt II, sayfa 1753-54.

6. Das S, Singer A. Controversies Of Perinatal Torsion Of The Spermatic Cord: A review survey and recommendations. $J$ Urol 1990; 143:231.

7. Allan WR and Brown RB. Torsion of the Testis: A review Of 58 cases. Br Med J 1966; 1: 1396.

8. Cass AS, Cass BP, Veeraraghan K. Immediate Exploration of the Unilateral Acute scrotum In Young Male Subjects. $J$ Urol 1980; 124: 829-31.

9. Murphy FL, Fletcher L, Pease P. Early scrotal exploration in all cases is the investigation and intervention of choice in the acute paediatric scrotum. Pediatr Surg Int. 2006; 22(5): 413-6. 
10. Baker LA, Sigman D, Mathews RI, Benson J, Docimo SG. An analysis of clinical outcomes using color doppler testicular ultrasound for testicular torsion. Pediatrics 2000; 105(3-1): 604-7.

11. Bickerstaff KI, Sethia K, Murie JA. Doppler ultrasonography in the diagnosis of acute scrotal pain. Br J Surg 1988; 75(3): 238-9.

12. Gatti JM, Patrick Murphy J. Current management of the acute scrotum. Semin Pediatr Surg 2007; 16(1): 58-63.

13. Nason GJ, Tareen F, McLoughlin D, McDowell D, Cianci F, Mortell A. Scrotal exploration for acute scrotal pain: a 10year experience in two tertiary referral paediatric units. Scand J Urol 2013; 47(5): 418-22.
14. Molokwu CN, Somani BK, Goodman CM. Outcomes of scrotal exploration for acute scrotal pain suspicious of testicular torsion: a consecutive case series of 173 patients. BJU Int 2011; 107(6): 990-3.

15. Nandi B, Murphy FL. Neonatal testicular torsion: a systematic literature review. Pediatr Surg Int 2011; 27(10): 1037-40.

16. Olguner M, Akgür FM, Aktuğ T, Derebek E. Bilateral asynchronous perinatal testicular torsion: a case report. J Pediatr Surg 2000; 35(9): 1348-9.

17. Melcer $Y$, Mendlovic S, Klin B, Keidar R, Lysyy O, Herman A, Maymon R. Fetal diagnosis of testicular torsion: what shall we tell the parents? Prenat Diagn 2015; 35(2): 167-73. 